\title{
Linezolid: The First Oxazolidinone Antimicrobial
}

\author{
Robert C. Moellering Jr., MD
}

Linezolid is the first of a new class of antimicrobial agents, the oxazolidinones, to be approved for clinical use in the United States and elsewhere. The drug is a totally synthetic compound, which lessens the likelihood of naturally occurring resistance mechanisms. It has excellent activity against virtually all important gram-positive pathogens, including methicillin-resistant staphylococci, penicillin-resistant pneumococci, macrolide-resistant streptococci, and vancomycin-resistant enterococci. Development of resistance to the compound has been infrequent thus far. Linezolid is $100 \%$ bioavailable, so it can be given in equal doses orally or parenterally. Its elimination half-life allows dosing twice per day, and alteration of drug dosage is not required in patients with impaired renal or hepatic function. Linezolid has approved indications for skin and soft tissue infections; lower respiratory tract infections; and vancomycin-resistant Enterococcus faecium infections, including cases with concurrent bacteremia. The drug has an acceptable profile of adverse events, but reversible myelosuppression has occurred in patients receiving high doses for more than 2 weeks.

Ann Intern Med. 2003;138:135-142.

For author affiliation, see end of text.
$\mathbf{E}_{\text {in }}^{\mathrm{ac}}$ ach antimicrobial agent developed for clinical use during the past 60 years has ultimately encountered problems with the emergence of resistant bacteria (1). The response of the pharmaceutical industry has been to develop a series of new agents active against resistant organisms (2). In recent years, there has been an increasing need for antimicrobial agents active against resistant gram-positive bacteria, such as methicillin-resistant staphylococci, penicillin-resistant pneumococci, and vancomycin-resistant enterococci (1). In this setting, it is disturbing to note that almost no new classes of antimicrobial agents have been discovered since 1980 (3). All but one of the new agents released during the past 20 years represent drugs discovered earlier and not previously developed or chemical modifications of earlier agents developed to increase potency (2). The oxazolidinones are an exception to this rule $(4,5)$. They represent a unique class of totally synthetic antimicrobial agents. Since they are not natural products, there are no preexisting specific resistance genes among grampositive bacteria. These agents also have a unique mechanism of action that precludes cross-resistance with currently available agents.

The oxazolidinones were originally developed as monoamine oxidase inhibitors for treatment of depression (6). It was subsequently discovered that they had antimicrobial activity, and E.I. DuPont de Nemours and Company developed the first oxazolidinone antimicrobial agents in the late 1970s for the control of bacterial and fungal foliage diseases of various plants, including tomatoes (6). Further chemical modification of these agents by scientists at DuPont resulted in compounds (including DuP-105 and DuP-721) that showed activity when given orally or parenterally to experimental animals and had a broad in vitro spectrum of activity that included most gram-positive bacteria, as well as several anaerobes and Mycobacterium tuberculosis (5). Because DuP-721 was demonstrated to have lethal toxicity in animal models (probably due to myelosuppression), these compounds were not developed further (6). However, scientists at Upjohn Laboratories continued to work with the oxazolidinones and produced a series of chemical modifications of the oxazolidinone nucleus. These efforts led to the discovery of two agents, eperezolid and linezolid, with excellent in vitro activity and markedly diminished toxicity compared with DuP-721. Although both eperezolid and linezolid showed excellent in vitro activity against gram-positive bacteria, linezolid (PNU-100766) was chosen for further clinical development because of its superior bioavailability and improved serum levels, which allowed twice-daily dosing (4). It is currently marketed under the trade name Zyvox (Pharmacia Corp., Peapack, New Jersey).

\section{Spectrum of Activity}

The oxazolidinones have excellent in vitro activity against all of the major gram-positive bacteria that are pathogenic in humans. Table 1 lists the species of grampositive bacteria in which $90 \%$ or more of the strains are inhibited by $4 \mu \mathrm{g}$ of linezolid per $\mathrm{mL}$ or less, the susceptibility breakpoint for staphylococci established by the U.S. Food and Drug Administration (FDA) (7). For Streptococcus pneumoniae and other streptococci, a breakpoint of 2 $\mu \mathrm{g} / \mathrm{mL}$ or less for susceptible strains has been set. There are no breakpoints for resistant streptococci or staphylococci because no resistant strains had been encountered when the breakpoints were set. For enterococci, $2 \mu \mathrm{g} / \mathrm{mL}$ or less indicates susceptibility, $4 \mu \mathrm{g} / \mathrm{mL}$ indicates intermediate susceptibility, and $8 \mu \mathrm{g} / \mathrm{mL}$ or greater indicates resistance. The U.S. National Committee for Clinical Laboratory Standards has established similar breakpoints.

Linezolid demonstrates in vitro activity against Neisseria gonorrhoeae and Neisseria meningitidis. It has only borderline activity (minimum inhibitory concentration of 4 to $16 \mu \mathrm{g} / \mathrm{mL}$ for $90 \%$ of strains) against Haemophilus influenzae and is inactive against Enterobacteriaceae and Pseudomonas species $(8,9)$. Gram-negative bacilli are probably intrinsically resistant because they possess efflux pumps that are effective against linezolid (13). Although linezolid possesses activity against "atypical organisms," including Legionella pneumophila, Mycoplasma pneumoniae, 


\section{Table 1. Organisms Routinely Susceptible to Linezolid*}

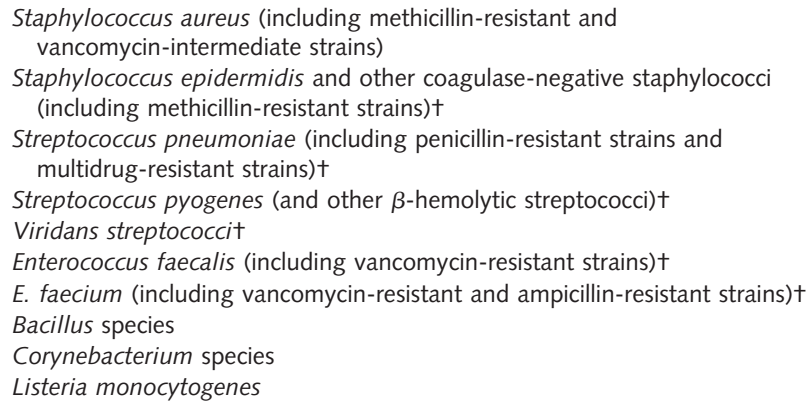

* Susceptibility is indicated by a minimum inhibitory concentration of $\leq 4 \mu \mathrm{g} / \mathrm{mL}$ for $>90 \%$ of strains. Data are based on references 4 and $8-12$.

$\dagger>90 \%$ susceptible to $\leq 2 \mu \mathrm{g}$ of linezolid per $\mathrm{mL}$.

and Chlamydia pneumoniae, there are not currently enough in vitro data available to evaluate their effectiveness against these organisms in vivo (8). Linezolid has good activity against many gram-positive anaerobes; its activity against Bacteroides fragilis is borderline (minimum inhibitory concentration of $4 \mu \mathrm{g} / \mathrm{mL}$ for $50 \%$ of strains), but it is bactericidal against these organisms (8). Of interest, linezolid exhibits relatively good in vitro activity against many strains of Mycobacterium tuberculosis (8) and has activity against the Mycobacterium avium complex and several rapidly growing mycobacteria, including Mycobacterium fortuitum, Mycobacterium chelonae, and Mycobacterium abscessus $(14,15)$. The clinical significance of the activity of linezolid against mycobacteria is not known, but, of interest, it is possible to produce oxazolidinone derivatives with even greater activity against mycobacteria (16). Linezolid also has excellent in vitro activity against Nocardia species (including Nocardia asteroides, Nocardia farcinica, Nocardia brasiliensa, and four other species) (17).

The activity of linezolid in combination with a variety of antimicrobial agents (including amoxicillin, ampicillin, aztreonam, cefotaxime, cefpodoxime, chloramphenicol, clavulanic acid, clindamycin, erythromycin, gentamicin, imipenem, oxacillin, penicillin, rifampin, and vancomycin) has been studied in vitro against staphylococci, pneumococci, enterococci, Escherichia coli, and Klebsiella pneumoniae (18). These studies were carried out by using the checkerboard method, which measures bacteriostatic, not bactericidal, interactions. In this system, the interaction of linezolid with other antimicrobial agents was almost invariably additive or indifferent and was rarely antagonistic or synergistic (18).

As is true for the macrolides, subinhibitory concentrations of linezolid have been shown to inhibit the expression of virulence factors by staphylococci and streptococci (19). Specifically, subinhibitory concentrations of the drug decrease hemolysin and coagulase production by Staphylococcus aureus and impair streptolysin $\mathrm{O}$ and DNAase production in vitro by streptococci. Moreover, subinhibitory concentrations of the drug potentiate the susceptibility of
Staphylococcus aureus and Streptococcus pyogenes to phagocytosis by human neutrophils (19). The exact clinical correlate of these in vitro findings remains to be determined.

\section{Mechanism of Action and Resistance}

The oxazolidinones are inhibitors of bacterial ribosomal protein synthesis (20-22), but unlike other antimicrobial agents that target the ribosome, the oxazolidinones appear to have a unique mechanism of action, stopping the first step in which bacteria assemble ribosomes from their dissociated subunits. They accomplish this by binding to a site on the 50S ribosomal subunit near its interface with the $30 \mathrm{~S}$ unit, thus preventing the formation of a $70 \mathrm{~S}$ initiation complex, which includes fMet transfer RNA, messenger RNA, and the two ribosomal subunits (20-22). No other known antimicrobial agent inhibits this process; therefore, there is no cross-resistance. Linezolid binds to the $50 \mathrm{~S}$ subunit at a site near that where the binding of chloramphenicol and lincomycin occurs, since it competes with these agents for the binding sites near the central region of domain $\mathrm{V}$ of the $23 \mathrm{~S}$ ribosomal RNA of the $50 \mathrm{~S}$ subunit $(21,22)$. Domain $\mathrm{V}$ is the peptidyl transferase center that catalyzes peptide bond formation. Unlike chloramphenicol and lincomycin, linezolid does not inhibit peptide bond formation and there is no cross-resistance between chloramphenicol or lincomycin and linezolid.

It is difficult to induce resistance to linezolid in vitro. It is possible, however, to produce mutants of linezolidresistant Staphylococcus aureus and Enterococcus faecalis by using serial passage on spiral gradient plates. It appears to be more difficult to generate mutants of Enterococcus faecium resistant to linezolid than for quinupristin-dalfopristin (22). The specific point mutations causing resistance in Staphylococcus aureus, Enterococcus faecalis, Enterococcus faecium, and other organisms have been mapped to several different locations in domain $\mathrm{V}$ of the $23 \mathrm{~S}$ ribosomal RNA of the $50 \mathrm{~S}$ subunit of the ribosome (23-25), and studies in resistant clinical isolates reveal similar mutations (26-28; Moellering RC Jr., Tsiodras S, Gold H, Meka V, Sakoulas G, Eliopoulos GM, et al. Unpublished data). Resistance to the oxazolidinones based on inactivation has not been demonstrated in any bacterial species tested.

Thus far, it appears that most patients whose organisms have developed resistance to linezolid during therapy have indwelling prosthetic devices and are receiving prolonged courses of the antibiotic (26-28). Most of the organisms developing resistance in this setting have been $E n$ terococcus faecium, but a single clinical isolate of linezolidresistant Staphylococcus aureus has recently been described (26). Like that of most inhibitors of ribosomal protein synthesis, the activity of linezolid against bacteria in vitro is considered "bacteriostatic" rather than "bactericidal." However, the drug exhibits in vitro killing (albeit slower than for most bactericidal agents) against streptococci, in- 
Linezolid: The First Oxazolidinone Antimicrobial $\mid$ REVIEW

Table 2. Pharmacokinetic Characteristics of Linezolid*

\begin{tabular}{|c|c|c|c|c|}
\hline \multirow[t]{2}{*}{ Dosage } & $\begin{array}{l}\text { Peak Serum } \\
\text { Concentration }\end{array}$ & $\begin{array}{l}\text { Trough Serum } \\
\text { Concentration }\end{array}$ & AUC & $\begin{array}{l}\text { Serum Elimination } \\
\text { Half-Life }\end{array}$ \\
\hline & \multicolumn{2}{|c|}{$\mu g / m L$} & $\mu g \times h$ per $m L$ & $h$ \\
\hline $400 \mathrm{mg}$ orally every $12 \mathrm{~h}$ & $11.00 \pm 4.37$ & $3.08 \pm 2.25$ & $73.40 \pm 33.50$ & $4.69 \pm 1.70$ \\
\hline $600 \mathrm{mg}$ orally every $12 \mathrm{~h}$ & $21.20 \pm 5.78$ & $6.15 \pm 2.94$ & $138.00 \pm 42.10$ & $5.40 \pm 2.06$ \\
\hline $600 \mathrm{mg}$ intravenously every $12 \mathrm{~h}$ & $15.10 \pm 2.52$ & $3.68 \pm 2.36$ & $89.70 \pm 31.00$ & $4.80 \pm 1.70$ \\
\hline
\end{tabular}

* Values presented with plus/minus signs are means \pm SD. Data are based on references $29-31$. AUC $=$ area under the curve.

cluding Streptococcus pneumoniae, and Staphylococcus aureus $(4,8)$.

\section{Pharmacokinetic Characteristics}

The major pharmacokinetic characteristics of linezolid are given in Tables 2 and 3. A standard dosage of $600 \mathrm{mg}$ every 12 hours is recommended for treatment of most serious infections except uncomplicated skin and skin structure infections, for which an oral dosage of $400 \mathrm{mg}$ every 12 hours is officially recommended (7). There are no current recommendations for alteration of the dose according to patients' weight or sex. Linezolid is $100 \%$ bioavailable, which means that similar serum levels are achieved whether the drug is given orally or intravenously. Maximum plasma concentrations are achieved 1 to 2 hours after an oral dose of the drug. Although taking the drug with food slightly delays its uptake, the total amount of drug absorbed is unchanged. The drug has low serum plasma protein binding (approximately 31\%) and is freely distributed to wellperfused tissues.

Linezolid is metabolized by oxidation of its morpholino ring, resulting in two metabolites: an aminoethoxyacetic acid metabolite and a hydroxyethyl glycine metabolite. The latter metabolite is formed by nonenzymatic oxidation. The drug does not induce cytochrome P450 enzymes and does not seem to be metabolized by cytochrome P450 in humans. In addition, it does not inhibit the activity of human P450 isoforms (7).

Approximately $30 \%$ to $35 \%$ of the parent compound is recovered in the urine, and none is found in feces. Most is metabolized as noted earlier (7). Therefore, the pharmacokinetic characteristics of linezolid are not markedly altered in patients with renal insufficiency, and no dosage requirement is officially recommended for patients with renal or hepatic insufficiency (Table 3). However, there is some accumulation of both metabolites in patients with impaired renal function, the clinical significance of which has not been determined. For that reason, the package insert states, "Given the absence of information on the clinical significance of accumulation of the primary metabolites, use of linezolid in patients with renal insufficiency should be weighed against the potential risks of accumulation of these metabolites. Both linezolid and the two metabolites are eliminated by dialysis" (7). There is no information on the effect of peritoneal dialysis on the pharmacokinetic characteristics of linezolid, but currently available data suggest that in patients receiving hemodialysis, supplemental or postdialysis doses should be administered (31). Although the official recommendations state that no dosage adjustment is necessary in patients with hepatic insufficiency, that is probably true only for patients with mild to moderate cases of the disorder. There simply are not enough data on the use of the drug in patients with severe hepatic insufficiency to provide specific recommendations at this time.

\section{CLiniCAL Use of Linezolid}

The FDA has approved linezolid for the treatment of vancomycin-resistant Enterococcus faecium infections, including cases with concurrent bacteremia. Linezolid is also approved for community-acquired pneumonia caused by Streptococcus pneumoniae (penicillin-susceptible strains only) or Staphylococcus aureus; nosocomial pneumonia caused by Staphylococcus aureus (methicillin-susceptible and methicillin-resistant strains) or Streptococcus pneumoniae (penicillin-susceptible strains); complicated skin and soft tissue infections caused by Staphylococcus aureus (methicillin-resistant and methicillin-susceptible strains), Streptococcus pyogenes, or Streptococcus agalactiae; and uncomplicated skin and soft tissue infections caused by Staphylococcus aureus (methicillin-susceptible strains only) or Streptococcus pyogenes (7). These indications are based on the results of phase III trials presented to the FDA. The data from these clinical trials are summarized in Table 4. The results of several of these studies have been published or submitted

\section{Table 3. Additional Pharmacokinetic Characteristics} of Linezolid*

\begin{tabular}{|cc}
\hline Characteristic & Value \\
Oral bioavailability, \% & 100 \\
Plasma protein binding, \% & 31 \\
Volume of distribution, $L$ & $40-50$ \\
Clearance & \\
Total, $m L / m i n$ & $100-200$ \\
Renal, $m L / m i n$ & $30-50$ \\
Nonrenal, $m L / m i n$ & $70-150$ \\
Parent compound recovered in urine, \% & $30-35$ \\
No dosage alteration recommended for hepatic or & \\
renal impairment & \\
\hline
\end{tabular}

* Data based on references 29-31. 21 January 2003 Annals of Internal Medicine $\mid$ Volume 138 • Number $2 \mid 137$ 
to peer-reviewed journals (32-34). In all of the studies completed so far, linezolid has been shown to be equivalent to its comparator. However, it should be noted that, although linezolid is indicated for community-acquired pneumonia on the basis of comparative trials, the comparators were drugs (cefpodoxime and ceftriaxone) that possess no activity against "atypical pathogens," including Chlamydia pneumoniae, Mycoplasma pneumoniae, and Legionella species (35). Linezolid also lacks good activity against Haemophilus influenzae. For these reasons, it should not be considered a first-line choice for communityacquired pneumonia at the present time. The drug has not been compared with newer agents, such as quinupristindalfopristin, because they were not approved for clinical use by the FDA when the studies were initiated.

In an interesting study that has not yet been published, two dosing regimens of linezolid were studied in patients infected with vancomycin-resistant enterococci (Data on file. Pharmacia Corp.). In this small study, the clinical cure rate in patients receiving linezolid, $600 \mathrm{mg}$ twice daily, was 39 of 44 patients $(88.6 \%)$ versus 28 of 38 patients $(73.7 \%)$ receiving $200 \mathrm{mg}$ twice daily. This difference was not statistically significant $(P=0.08)$, but there was a statistically significant difference in microbiological outcome among evaluable patients; microbiological success was noted in 30 of 35 patients receiving the higher dose (85.7\%) compared with 17 of 29 patients receiving the lower dose $(58.6 \%)(P=0.01)$. No comparative trials of linezolid in patients with endocarditis, osteomyelitis, or meningitis have been performed. Thus, evaluation of the potential of linezolid for these infections currently rests only on studies in animal models.

A recently published study of linezolid using a rabbit model of staphylococcal endocarditis suggests that linezolid may be efficacious for endocarditis due to methicillinsusceptible Staphylococcus aureus if trough concentrations are maintained at approximately the minimum inhibitory concentration of the infecting organism (36). It should be noted that the effective dose of linezolid in this model was considerably higher than the currently approved human doses because of the shorter half-life of the drug in rabbits; nonetheless, linezolid demonstrated efficacy and appeared as efficacious as vancomycin at the higher doses. In another recently published study, linezolid was demonstrated to exhibit modest activity in a rat model of endocarditis due to vancomycin-resistant Enterococcus faecium (37). The comparator in this study was vancomycin, which, not surprisingly, was ineffective. Neither of these studies provides sufficient data to determine whether linezolid will be effective for staphylococcal or enterococcal endocarditis in humans, and further data are clearly necessary to assess its potential here.

The situation with experimental osteomyelitis is even less clear-cut. A recent study by Patel and colleagues (38) suggests that linezolid was no better than placebo for osteomyelitis due to methicillin-susceptible Staphylococcus aureus in a rat model; cefazolin demonstrated slightly greater efficacy. In contrast, a study of rabbit osteomyelitis caused by a methicillin-resistant strain of Staphylococcus aureus showed that linezolid was as efficacious as vancomycin (Mader J. Personal communication). A recent case report describes the successful treatment of vertebral osteomyelitis with linezolid in a patient who was undergoing hemodialysis and had bacteremia with methicillin-resistant Staphylococcus aureus and vancomycin-resistant enterococci (39). There is also a report of two patients with prosthetic hip infections due to methicillin-resistant Staphylococcus aureus that were apparently cured by linezolid without removal of the prosthesis, although the follow-up periods to ascertain cure were only 8 and 9 months (40).

No clinical data are currently available on the use of linezolid for meningitis in humans. A recent study using the rabbit meningitis model studied the efficacy of linezolid against penicillin-sensitive and penicillin-resistant pneumococci (41). The authors noted that linezolid showed good penetration into the cerebrospinal fluid of

Table 4. Phase III Clinical Trials of Linezolid*

\begin{tabular}{|c|c|c|c|c|c|}
\hline Trial & Linezolid Dosage & Comparator Dosage & Linezolid & Comparator & $P$ Value \\
\hline Uncomplicated SSTI & $400 \mathrm{mg}$ orally twice daily for $7-14 \mathrm{~d}$ & $\begin{array}{l}\text { Oral clarithromycin, } 250 \mathrm{mg} \text { twice daily, } \\
\text { for } 7-14 \mathrm{~d}\end{array}$ & $283 / 310(91.3)$ & $262 / 301(87.0)$ & 0.09 \\
\hline Complicated SSTI & $600 \mathrm{mg}$ twice daily, IV or orally, for $10-21 \mathrm{~d}+$ & $\begin{array}{l}\text { IV oxacillin, } 2 \mathrm{~g} / \mathrm{d} \text {, and oral dicloxacillin, } \\
500 \mathrm{mg} / \mathrm{d} \text {, for } 10-21 \mathrm{~d} t\end{array}$ & 264/291 (90.7) & $259 / 300(86.3)$ & NS \\
\hline Hospitalized CAP & $600 \mathrm{mg}$ twice daily, IV or orally, for 7-14 d† & $\begin{array}{l}\text { IV ceftriaxone, } 1 \mathrm{~g} \text { twice daily, and oral } \\
\text { cefpodoxime, } 200 \mathrm{mg} \text { twice daily, } \\
\text { for } 7-14 \mathrm{~d}\end{array}$ & $247 / 272(90.8)$ & $225 / 254(88.6)$ & NS \\
\hline $\begin{array}{l}\text { Hospital-acquired } \\
\text { pneumonia }\end{array}$ & $600 \mathrm{mg}$ IV twice daily for 7-21 d‡ & $\begin{array}{l}\text { IV vancomycin, } 1 \mathrm{~g} \text { twice daily, } \\
\text { for } 7-21 \mathrm{d \neq}\end{array}$ & $71 / 107(66.4)$ & $62 / 91(68.1)$ & NS \\
\hline
\end{tabular}

* Data based on references 32-35. CAP = community-acquired pneumonia; IV = intravenous; NS = not significant; SSTI = skin and soft tissue infections.

+ Add aztreonam if gram-negative bacilli are suspected.

$\ddagger$ Plus aztreonam.

$138 \mid 21$ January $2003 \mid$ Annals of Internal Medicine $\mid$ Volume $138 \bullet$ Number 2 
rabbits (mean $[ \pm S D], 38 \% \pm 4 \%$ ). It seemed to be less effective than ceftriaxone against a penicillin-susceptible strain of Staphylococcus pneumoniae, and against a penicillin-resistant strain, the killing rates for linezolid were slightly inferior to those with a regimen of ceftriaxone plus vancomycin. The authors noted that linezolid was "marginally bactericidal" at concentrations 5 times and 10 times above the minimum inhibitory concentration of the test pneumococcal strain. Thus, pending further information, this certainly does not constitute sufficient evidence to begin routine clinical use of linezolid for pneumococcal (or other bacterial) meningitis.

In eradication of colonizing bacteria, linezolid has thus far had a mixed success rate. It was shown to be initially efficacious in the eradication of the nasal carriage of Staphylococcus aureus (42). However, the eradication was transient and most patients were recolonized after 30 days (42). Linezolid has been completely ineffective in eradicating vancomycin-resistant enterococci from the stool (Data on file. Pharmacia Corp.).

\section{AdVERSE EfFECTS}

Overall, linezolid has generated little toxicity and produced few adverse effects in phase III clinical trials (7). There is no evidence of significant adverse effects on liver function, renal function, or hematologic variables. However, in the early clinical trials, incidence of reversible thrombocytopenia was slightly higher (but statistically nonsignificant) in patients receiving linezolid than in controls (7). It should be noted that all of these trials were relatively short and used standard dosages that did not exceed $1200 \mathrm{mg} / \mathrm{d}$. Because the original oxazolidinones were known to be monoamine oxidase inhibitors, particular attention has been paid to the question of whether evidence of adverse interaction with drugs known to be metabolized by monoamine oxidase would occur in patients treated with linezolid. An enhanced pressor response has been seen in patients taking certain adrenergic agents, including phenylpropanolamine and pseudoephedrine, and it is specifically noted that the doses of these drugs should be reduced in patients receiving linezolid (7). Recently completed studies show no evidence of interaction of linezolid with oral or inhaled albuterol (Data on file. Pharmacia Corp.). Thus far, there has also been no evidence of interaction with serotonergic agents, including dextromethorphan (7), meperidine (Data on file. Pharmacia Corp.), and the selective serotonin reuptake inhibitor paroxetine hydrochloride (Data on file. Pharmacia Corp.). Therefore, it appears that the potential for significant adverse effects due to monoamine oxidation inhibition by linezolid is remote, at best.

As noted earlier, virtually all of the oxazolidinones studied to date have shown the potential for reversible myelosuppression in animals. Indeed, dose-dependent and time-dependent myelosuppression was noted in dogs and rats receiving prolonged, high-dose therapy with linezolid in preclinical trials (7). Except for a few cases of reversible thrombocytopenia, no significant myelosuppression was noted in the phase III trials of the drug. However, reversible myelosuppression with red-cell hypoplasia after therapy with linezolid has recently been reported (43). Postmarketing surveillance uncovered 18 reasonably welldocumented cases of thrombocytopenia or reversible anemia associated with the use of linezolid from 18 April to 18 October 2000 . These included 5 patients with anemia, 9 with thrombocytopenia, and 4 with neutropenia or anemia and thrombocytopenia after linezolid therapy (Data on file. Pharmacia Corp.). Many of these patients were receiving concomitant medications known to cause potential bone marrow suppression, and many had complex illnesses. Coupled with the data from preclinical and clinical trials, this led the FDA Medical Products Reporting and Safety Information Program to issue a report that myelosuppression (including anemia, leukopenia, pancytopenia, and thrombocytopenia) has been documented in patients receiving linezolid. It is now recommended that complete blood counts be monitored weekly in patients who receive linezolid, especially those receiving the drug for more than 2 weeks, those with preexisting myelosuppression, those receiving concomitant drugs that produce bone marrow suppression, and those with chronic infection who have received previous or concomitant antibiotic therapy. There have been no cases of aplastic anemia in patients receiving linezolid, and all cases of myelosuppression documented thus far have been reversible after discontinuation of therapy with the drug.

\section{Discussion}

Linezolid is a new antimicrobial agent with a broad spectrum of activity against virtually all important grampositive bacterial pathogens. It has a unique mechanism of action, which means that there is no cross-resistance with other classes of antimicrobial agents. In addition, since it is a totally synthetic compound, there is no natural reservoir of resistance. Like most other inhibitors of protein synthesis, linezolid is primarily bacteriostatic (although it has shown some "slow bactericidal activity" in animal models). It has been quite effective in clinical trials, where it has been used to treat skin and skin structure infections, respiratory tract infections, and severe systemic infections (including bacteremia) due to vancomycin-resistant enterococci. Its excellent activity against both vancomycin-resistant Enterococcus faecalis and Enterococcus faecium makes it a particularly attractive drug for infection with vancomycinresistant enterococci.

Although linezolid is indicated for communityacquired pneumonia, it is not currently considered a first- or second-line drug for this or other community-acquired respiratory tract infections. No data suggest clinical superiority to $\beta$-lactams for infections due to susceptible staph-

21 January 2003 Annals of Internal Medicine $\mid$ Volume 138 • Number 2|139 
ylococci or streptococci. There are not enough clinical data to determine whether the drug will be effective in patients with staphylococcal or enterococcal endocarditis or pneumococcal meningitis. Available animal data on osteomyelitis are conflicting, so it is impossible to draw conclusions on the efficacy of linezolid for this important indication despite anecdotal case reports of success. Emergence of resistance during therapy has already been documented for both enterococci and Staphylococcus aureus, although the latter represents only a single isolate so far. Resistance has also been found in fecal enterococci in patients receiving linezolid (44). The systemic infections in which resistance is most likely to occur usually involve seriously ill patients with indwelling prosthetic devices. Although no clinical evidence supports the concept, it may be possible to prevent the emergence of resistance in such settings (especially when it is impossible to remove the prosthetic device) by adding a second agent to which the organism is susceptible, such as erythromycin, doxycycline, or chloramphenicol. Chloramphenicol, however, would most likely be problematic because of the possibility of enhanced myelosuppression with two agents known to have this adverse effect. Indeed, myelosuppression seems to be a side effect that must be watched for in patients receiving long-term courses of linezolid or those with underlying conditions predisposing them to bone marrow suppression. Myelosuppression with linezolid therapy has been relatively infrequent and has always been reversible when therapy with the drug has been discontinued.

In vitro studies suggest that linezolid may be useful in treating certain mycobacterial infections (although newer analogues are being developed with even more activity than linezolid against mycobacteria) and Nocardia infections. However, there are no clinical data to assess this potential at the present time. Because linezolid does not induce or inhibit P450 enzymes and is not metabolized by them in the liver, drug-drug interactions with the many agents that do interact with this system are unlikely. Enhanced pressor responses have been seen with phenylpropanolamine and pseudoephedrine in patients receiving linezolid, so these drugs should be avoided or given in reduced doses in this setting. Interaction with other drugs that are metabolized by monoamine oxidase does not seem to be a problem. The fact that linezolid is $100 \%$ bioavailable when given orally makes dosing convenient and should lead to shorter hospital stays in patients requiring therapy for infection with resistant gram-positive organisms. Indeed, a recent study suggests that linezolid use reduces length of hospital stay in patients with known or suspected methicillin-resistant staphylococcal infections compared with vancomycin (45). These observations should be balanced against the cost of linezolid; it is relatively expensive, especially for outpatient use $(\$ 53.00$ for one $600-\mathrm{mg}$ tablet or $30 \mathrm{~mL}$ of oral suspension and $\$ 72.00$ for one $600-\mathrm{mg}$ intravenous vial) (46).

The other recently released drug for the treatment of multiresistant gram-positive infections is quinupristin- dalfopristin $(5,47,48)$. Quinupristin-dalfopristin is effective in vitro against all of the major gram-positive coccal pathogens except Enterococcus faecalis, which are naturally resistant. Unlike linezolid, quinupristin-dalfopristin is available only for intravenous administration. It has, however, been shown to be efficacious in the treatment of severe infection with vancomycin-resistant Enterococcus faecium and methicillin-resistant Staphylococcus aureus. It is bactericidal against some but not all of these organisms. No clinical trials thus far have compared the efficacy of quinupristin-dalfopristin with that of linezolid. Such trials are clearly necessary to determine the relative efficacy and safety of these two new antimicrobial agents.

Several other agents with activity against multidrugresistant gram-positive pathogens are currently in the pipeline, including oritavancin and daptomycin (5). If these drugs are ultimately released for clinical use, it will be imperative to set up clinical trials comparing them with the currently available agents if we are to be able to determine relative efficacy and safety. Until additional trials are available, clinicians are left with the available data, which clearly show that linezolid is clinically effective against several types of bacteria resistant to $\beta$-lactams, vancomycin, and a host of other agents. Early data demonstrate that linezolid will not be immune from the development of resistance, especially among enterococci, which comes as no real surprise. It seems that the major adverse effect of linezolid (reversible myelosuppression) can be managed by carefully observing hematologic variables, especially in patients receiving prolonged courses or with underlying conditions predisposing them to myelosuppression. On balance, linezolid represents a significant advance in the therapy of resistant gram-positive infections. Other analogues currently under development may further expand the promise of oxazolidinones as a new and interesting class of antimicrobial agents.

From Beth Israel Deaconess Medical Center, Boston, Massachusetts.

Potential Financial Conflicts of Interest: Dr. Moellering has served as a consultant to the anti-infective therapy groups at DuPont Pharmaceuticals (formerly DuPont Merck Pharmaceuticals, a division of E.I. DuPont de Nemours, Wilmington, Delaware), Pharmacia (formerly Upjohn Laboratories, Kalamazoo, Michigan), and Aventis Pharmaceuticals (formerly Rhône-Poulenc Rorer Pharmaceuticals, Inc., Collegeville, Maryland). In addition, he has received funding for basic laboratory research (not clinical research) from DuPont Merck Pharmaceuticals, Upjohn Laboratories, and Rhône-Poulenc Rorer Pharmaceuticals, Inc.

Requests for Single Reprints: Robert C. Moellering Jr., MD, Department of Medicine, Beth Israel Deaconess Medical Center, 110 Francis Street, Suite 6A, Boston, MA 02215.

\section{References}

1. Gold HS, Moellering RC Jr. Antimicrobial-drug resistance. N Engl J Med. 1996;335:1445-53. [PMID: 8875923]

2. Moellering RC Jr. Past, present, and future of antimicrobial agents. Am J 
Med. 1995;99:11S-18S. [PMID: 8585528]

3. Silver L, Bostian K. Screening of natural products for antimicrobial agents. Eur J Clin Microbiol Infect Dis. 1990;9:455-61. [PMID: 2226472]

4. Ford C, Hamel J, Stapert D, Moerman J, Hutchinson D, Barbachyn M, et al. Oxazolidinones: a new class of antimicrobials. Infections in Medicine. 1999; 16:435-45.

5. Moellering RC Jr. A novel antimicrobial agent joins the battle against resistant bacteria [Editorial]. Ann Intern Med. 1999;130:155-7. [PMID: 10068364]

6. Brickner SJ. Oxazolidinone antibacterial agents. Current Pharmaceutical Design. 1996;2:175-94.

7. Zyvox [package insert]. Kalamazoo, MI: Pharmacia \& Upjohn; 2000.

8. Diekema DI, Jones RN. Oxazolidinones: a review. Drugs. 2000;59:7-16. [PMID: 10718097]

9. Zurenko GE, Yagi BH, Schaadt RD, Allison JW, Kilburn JO, Glickman SE, et al. In vitro activities of U-100592 and U-100766, novel oxazolidinone antibacterial agents. Antimicrob Agents Chemother. 1996;40:839-45. [PMID: 8849237]

10. Henwood CJ, Livermore DM, Johnson AP, James D, Warner M, Gardiner A. Susceptibility of gram-positive cocci from 25 UK hospitals to antimicrobial agents including linezolid. The Linezolid Study Group. J Antimicrob Chemother. 2000;46:931-40. [PMID: 11102412]

11. Cercenado E, García-Garrote F, Bouza E. In vitro activity of linezolid against multiply resistant Gram-positive clinical isolates. J Antimicrob Chemother. 2001; 47:77-81. [PMID: 11152434]

12. Eliopoulos GM, Wennersten CB, Gold HS, Moellering RC Jr. In vitro activities in new oxazolidinone antimicrobial agents against enterococci. Antimicrob Agents Chemother. 1996;40:1745-7. [PMID: 8807077]

13. Buysse JM, Demyan WF, Dunyak DS, Stapert D, Hamel JC, Ford CW. Mutation of the AcrAB antibiotic efflux pump in Escherichia coli confers susceptibility to oxazolidinone antibiotics [Abstract]. In: Program and Abstracts of the 36th Interscience Conference on Antimicrobial Agents and Chemotherapy, 15-18 September 1996, New Orleans, Louisiana. Washington, DC: American Soc for Microbiology; 1998. Abstract no. C42.

14. Wallace RJ Jr, Brown-Elliott BA, Ward SC, Crist CJ, Mann LB, Wilson RW. Activities of linezolid against rapidly growing mycobacteria. Antimicrob Agents Chemother. 2001;45:764-7. [PMID: 11181357]

15. Peters J, Kondo KL, Lee RK, Lin CK, Inderlied CB. In-vitro activity of oxazolidinones against Mycobacterium avium complex. J Antimicrob Chemother. 1995;35:675-9. [PMID: 7592181]

16. Murray RW, Schaadt RD, Zurenko GE, Marotti KR. Ribosomes from an oxazolidinone-resistant mutant confer resistance to eperezolid in a Staphylococcus aureus cell-free transcription-translation assay. Antimicrob Agents Chemother. 1998;42:947-50. [PMID: 9559817]

17. Brown BA, Ward SC, Crist CJ, Mann LB, Wilson RW, Wallace RJ Jr. In vitro activity of linezolid against multiple species of Nocardia: a new drug of choice for a difficult disease? [Abstract] In: Program and Abstracts of the 100th General Meeting of the American Society for Microbiology, 21-25 May 2000, Los Angeles, California. Washington, DC: American Soc for Microbiology; 2000. Abstract no. U-57.

18. Sweeney MT, Baldwin KF, Zurenko GE. In vitro activity of linezolid combined with other antibacterial agents [Abstract]. In: Program and Abstracts of the 39th Interscience Conference on Antimicrobial Agents and Chemotherapy, 26-29 September 1999, San Francisco, California. Washington, DC: American Soc for Microbiology; 1999. Abstract no. 1252.

19. Gemmell GC, Ford CW. Expression of virulence factors in gram-positive cocci exposed to sub-MIC levels of linezolid [Abstract]. In: Program and Abstracts of the 39th Interscience Conference on Antimicrobial Agents and Chemotherapy, 26-29 September 1999, San Francisco, California. Washington, DC: American Soc for Microbiology; 1999. Abstract no. 1537.

20. Daly JS, Eliopoulos GM, Willey S, Moellering RC Jr. Mechanism of action and in vitro and in vivo activities of S-6123, a new oxazolidinone compound. Antimicrob Agents Chemother. 1988;32:1341-6. [PMID: 3058018]

21. Lin AH, Murray RW, Vidmar TJ, Marotti KR. The oxazolidinone eperezolid binds to the $50 \mathrm{~S}$ ribosomal subunit and competes with binding of chloramphenicol and lincomycin. Antimicrob Agents Chemother. 1997;41:2127-31. [PMID: 9333036]

22. Swaney SM, Aoki H, Ganoza MC, Shinabarger DL. The oxazolidinone linezolid inhibits initiation of protein synthesis in bacteria. Antimicrob Agents Chemother. 1998;42:3251-5. [PMID: 9835522]

23. Prystowsky J, Siddiqui F, Chosay J, Shinabarger DL, Millichap J, Peterson LR, et al. Resistance to linezolid: characterization of mutations in rRNA and comparison of their occurrences in vancomycin-resistant enterococci. Antimicrob Agents Chemother. 2001;45:2154-6. [PMID: 11408243]

24. Xiong L, Kloss P, Douthwaite S, Andersen NM, Swaney S, Shinabarger DL, et al. Oxazolidinone resistance mutations in $23 \mathrm{~S}$ rRNA of Escherichia coli reveal the central region of domain $\mathrm{V}$ as the primary site of drug action. J Bacteriol. 2000;182:5325-31. [PMID: 10986233]

25. Kloss P, Xiong L, Shinabarger DL, Mankin AS. Resistance mutations in 23 $S$ rRNA identify the site of action of the protein synthesis inhibitor linezolid in the ribosomal peptidyl transferase center. J Mol Biol. 1999;294:93-101. [PMID: 10556031]

26. Tsiodras S, Gold HS, Sakoulas G, Eliopoulos GM, Wennersten C, Venkataraman L, et al. Linezolid resistance in a clinical isolate of Staphylococcus aureus [Letter]. Lancet. 2001;358:207-8. [PMID: 11476839]

27. Gonzales RD, Schreckenberger PC, Graham MB, Kelkar S, DenBesten K, Quinn JP. Infections due to vancomycin-resistant Enterococcus faecium resistant to linezolid [Letter]. Lancet. 2001;357:1179. [PMID: 11323048]

28. Zurenko G, Todd WM, Hafkin BA. Development of linezolid-resistant Enterococcus faecium in two compassionate use programs patients treated with linezolid [Abstract]. In: Program and Abstracts of the 39th Interscience Conference on Antimicrobial Agents and Chemotherapy, 26-29 September 1999, San Francisco, California. Washington, DC: American Soc for Microbiology; 1999. Abstract no. 848.

29. Stalker DJ, Wajszczuk CP, Batts DH. Linezolid safety, tolerance, and pharmacokinetics following oral dosing twice daily for 14.5 days [Abstract]. In: Program and Abstracts of the 37th Interscience Conference on Antimicrobial Agents and Chemotherapy, 28 September-1 October 1997, Toronto, Ontario, Canada. Washington, DC: American Soc for Microbiology; 1997. Abstract no. A-115.

30. Stalker DJ, Wajszczuk CP, Batts DH. Linezolid safety, tolerance, and pharmacokinetics following oral dosing twice daily for 7.5 days [Abstract]. In: Program and Abstracts of the 37th Interscience Conference on Antimicrobial Agents and Chemotherapy, 28 September-1 October 1997, Toronto, Ontario, Canada. Washington, DC: American Soc for Microbiology; 1997. Abstract no. A-116.

31. Brier ME, Stalker DJ, Aronoff GR, Batts DH, Ryan KK, O'Grady MA, et al. Pharmacokinetics of linezolid in subjects with varying degrees of renal function and on dialysis [Abstract]. In: Program and Abstracts of the 38th Interscience Conference on Antimicrobial Agents and Chemotherapy, 24-27 September 1998, San Diego, California. Washington, DC: American Soc for Microbiology; 1998. Abstract no. A-54.

32. Plouffe JF. Emerging therapies for serious gram-positive bacterial infections: a focus on linezolid. Clin Infect Dis. 2000;31 Suppl 4:S144-9. [PMID: 11017864]

33. Stevens DL, Smith LG, Bruss JB, McConnell-Martin MA, Duvall SE, Todd WM, et al. Randomized comparison of linezolid (PNU-100766) versus oxacillin-dicloxacillin for treatment of complicated skin and soft tissue infections. Antimicrob Agents Chemother. 2000;44:3408-13. [PMID: 11083648]

34. Rubinstein E, Cammarata S, Oliphant T, Wunderink R. Linezolid (PNU100766) versus vancomycin in the treatment of hospitalized patients with nosocomial pneumonia: a randomized, double-blind, multicenter study. Clin Infect Dis. 2001;32:402-12. [PMID: 11170948]

35. Cammarata SK, San Pedro GS, Timm JA, Hempsall KA, Todd WM, Oliphant TH, et al. Comparison of Linezolid versus ceftriaxone/cefpodoxime in the treatment of hospitalized patients with community-acquired pneumonia [Abstract]. In: Abstracts of the European Congress of Clinical Microbiology and Infectious Diseases, 28-31 May 2000, Stockholm, Sweden.

36. Oramas-Shirey MP, Buchanan LV, Dileto-Fang CL, Dailey CF, Ford CW, Batts DH, et al. Efficacy of linezolid in a staphylococcal endocarditis rabbit model. J Antimicrob Chemother. 2001;47:349-52. [PMID: 11222569]

37. Patel R, Rouse MS, Piper KE, Steckelberg JM. Linezolid therapy of vancomycin-resistant Enterococcus faecium experimental endocarditis. Antimicrob Agents Chemother. 2001;45:621-3. [PMID: 11158767]

38. Patel R, Piper KE, Rouse MS, Steckelberg JM. Linezolid therapy of Staphylococcus aureus experimental osteomyelitis. Antimicrob Agents Chemother. 2000; 44:3438-40. [PMID: 11083654]

39. Melzer M, Goldsmith D, Gransden W. Successful treatment of vertebral 
osteomyelitis with linezolid in a patient receiving hemodialysis and with persistent methicillin-resistant Staphylococcus aureus and vancomycin-resistant Enterococcus bacteremias. Clin Infect Dis. 2000;31:208-9. [PMID: 10913433]

40. Bassetti M, Di Biagio A, Cenderello G, Del Bono V, Palermo A, Cruciani M, et al. Linezolid treatment of prosthetic hip infections due to methicillinresistant Staphylococcus aureus (MRSA). J Infect. 2001;43:148-9. [PMID: 11676523]

41. Cottagnoud P, Gerber CM, Acosta F, Cottagnoud M, Neftel K, Täuber MG. Linezolid against penicillin-sensitive and -resistant pneumococci in the rabbit meningitis model. J Antimicrob Chemother. 2000;46:981-5. [PMID: 11102418]

42. Hyatt JM, Ballow CH, Forrest A, Turnak MR, Stalker DJ, Schentag JJ. Safety and efficacy of linezolid in the eradication of nasal Staphylococcus aureus [Abstract]. In: Program and Abstracts of the 38th Interscience Conference on Antimicrobial Agents and Chemotherapy, 24-27 September 1998, San Diego, California. Washington, DC: American Soc for Microbiology; 1998. Abstract no. A-4.

43. Green SL, Maddox JC, Huttenbach ED. Linezolid and reversible myelosuppression [Letter]. JAMA. 2001;285:1291. [PMID: 11255382]
44. Bassetti M, Farrel PA, Allan DA, Dembry LM, Opal JE. Emergence of linezolid-resistant Enterococcus faecium in the gastrointestinal tract during treatment of vancomycin-resistant enterococcal infections [Abstract]. In: Program and Abstracts of the 41st Interscience Conference on Antimicrobial Agents and Chemotherapy, 22-25 September 2001, Chicago, Illinois. Washington, DC: American Soc for Microbiology; 2001. Abstract no. K-1193.

45. Li Z, Willke RJ, Pinto LA, Rittenhouse BE, Rybak MJ, Pleil AM, et al. Comparison of length of hospital stay for patients with known or suspected methicillin-resistant Staphylococcus species infections treated with linezolid or vancomycin: a randomized, multicenter trial. Pharmacotherapy. 2001;21:263-74. [PMID: 11256381]

46. Linezolid (Zyvox). Med Lett Drugs Ther. 2000;42:45-6. [PMID: 10859730] 47. Livermore DM. Quinupristin/dalfopristin and linezolid: where, when, which and whether to use? J Antimicrob Chemother. 2000;46:347-50. [PMID: 10980159]

48. Moellering RC. Quinupristin/dalfopristin: therapeutic potential for vancomycin-resistant enterococcal infections. J Antimicrob Chemother. 1999;44 Suppl A:25-30. [PMID: 10511394]

The kitchen, like the other rooms of the house, was skimpy and confined; I darted over the ripples of the linoleum floor in three steps, opened the refrigerator, and groped in the dark interior for the jar of ice water. Then I lifted the jar and gulped, my eyes moistening over in appreciation even as I sensed a twitch of guilt. I knew I shouldn't be drinking from the jar. One didn't swap germs promiscuously at a time when common infections sometimes spelled doom. Surfaces wiped clean, made sterile; raw food was triply rinsed and purified. As people moved through an invisible blizzard of evil microbes, there was much random mortality. Mr. Max Weissberger, owner of the leading department store in the two nearby, scratched a pimple on his nose on Thursday and by Monday he was dead.

... It could be a scary world, pre-penicillin ...

William Styron

A Tidewater Morning: Three Tales from Youth

New York: Random House; 1993:93

Submitted by:

James J. Castles, MD

University of California, Davis

Davis, CA 95616

Submissions from readers are welcomed. If the quotation is published, the sender's name will be acknowledged. Please include a complete citation (along with page number on which the quotation was found), as done for any reference.-The Editor 